\title{
Baudelaire, Crítico de Arte
}

\author{
Por Américo Ferrari
}

Es sumamente difícil, por no decir imposible, separar en la obra de Charles Baudelaire al crítico del poeta. Como pocos escritores, como ninguno quizás, Baudelaire vivió y padeció bajo el signo permanente de la poesía, de una poesía exclusiva, celosa, omnipresente, que desborda de todos sus escritos e invade su vida y su obra con la fuerza que sólo la intuición constante del misterio en la vida $y$ en el arte puede dar al poeta que se hace portavoz e introductor del mito. Baudelaire fué esencialmente poeta, y su obra entera de crítico, que ocupa paralelamente a su obra en verso, toda su vida, no és sino un eco y. por decirlo así, una derivación de su sensibilidad poética. Baudelaire mismo se explica abierta y explícitamente sobre este punto o'Seria un! acontecimiento perfectamente nuevo en la historia de las artes que un crítico se hiciera poeta: sería esto un trastornamiento de todas las leyes psíquicas, una monstruosidad: por el contrario, todos los grandes poetas se hacen naturalmente, fatalmente, críticos", dice llanamente en su estudio sobre la música de Wagner. La verdadera crítica, pues, la crítica creadora y constructura, nos es presentada como una función de la poesía, como un dominio anexo al temperamento poético en que el poeta se sitúa para confrontar su subjetividad con la subjetividad de un artista': de esta confrontación nacerá el estudio crítico, todo lleno de vida y de pasión. Tal concepción implica, en definitiva, la existencia de dos métodos de crítica : la una, académica y dirigida sobre el detalle técnico, la otra poética, subjetiva y apasionada, e interesada sobre todo en la impresión de conjunto de la obra de arte. "Yo creo sinceramente -dice Baudelaire- que la mejor crítica, es la que es divertida y 
poética; no aquélla, fría y algebraica que bajo el pretexto de explicarlo todo no tiene ni odio ni amor, y se despoja voluntariamente de toda especie de temperamento; sino - ya que un cuadro es la naturaleza reflejada por un artista-, aquélla que será la naturaleza reflejada por un artista inteligente y sensible. Assí la mejor reseña de un cuadro - agrega curiosamente Baudelaire- podrá ser un soneto o una elegía". El poema de "Les Fleurs du Mal", "Los Faros", constituye una magnífica aplicación de esta teoría. En ocho cuartetos Baudelaire describe -la palabra describir es quizás inexacta-, digamos mejor, evoca la obra de ocho pintores : Rubens, Leonardo, Rembrandt, Miguel Ångel, Puget, Watteau, Goya y Delacroix. Cada estrofa del poema nos presenta un universo: el universo cargado de misterio, habitado por la pléyade de imágenes evocadoras que crea en el alma del poeta la obra de cada artista. Poeta, Baudelaire se empeña en expresar fielmente la impresión misteriosa y supernatural de la honra del artista genial. "Los Faros", un poema, nos ofrece asi en su estado más prístino, una muestra del método crítico de Baudelaire, que consiste ante todo en captar lo esencial de la obra de cada pintor y hacer corresponder a la que Bqudelaire llama "la idea central o directora" de una pintura, las misteriosas vibraciones que ésta suscita en el alma del poeta-crítico :

"Léonáld de Vinci, miroir profond et sombre,

Oú des anges charmants, avec un doux souris Tout chargé de fnystere, apparaissent à l'ombre

Des glaciers et des pins qui ferment leur pays";

He aquí, en cuatro versos de extraordinaria simplicidad, la traducción en el alma del poeta del colosal universo pictórico de Leonardo: la descripción es una evocación que reposa sobre el poder sugestivo de las ideas de profundidad, sombra, misterio (Baudelaire sugiere así la presencia en la pintura de Leonardo de tonos obscuros), y se cierra con la fugaz evocación final de un horizonte de árboles y nieve, (sugerencia de colores claros, blan$\cos$ y verdes).

Veamos otra estrofa :

"Delacroix, lac de sang hanté de mauvais anges,

Ombragé par un bols de sapins toujours vert,

Ou, sous un ciel chagrin, des fanfares étranges

Passent, comme un soupir étouffé de Weber"; 
Aquí también, en cuatro versos, está representado el Delacroix que amaba Baudelaire: el "armonista" de los colores, en cuya obra "el verde canta la gloria del rojo" (esta ponderación de rojo y verde place a nuestro espíritu", decía el poeta), y el artista melodioso que Baudelaire describe a menudo en términos musicales y cuyos colores corresponden, en su aguda sensibilidad estética, a los sonidos. Esta descripción por evocación, este dejar de lado los detalles para ir directamente a la estructura esencial de la obra de un pintor, mediante una enumeración poética de cualidades, que recurre a menudo a la sensación de tipo no visual, o al halo dramático y poético que circunda a un cuadro, constituyen ya la base sobre la cual se sustentará la obra propiamente crítica de Baudelaire, obra que inaugura un nuevo método y una nueva concepción de la crítica de arte. Cierto es que el poema "Los Faros", no es de ninguna manera un trozo de crítica propiamente dicha, $\mathrm{y}$ a nadie se le ocurriría hacerlo pasar por tal : en tanto que poesía pura el poema excluye toda racionalización, todo análisis y toda intención polémica, elementos siempre presentes en las reseñas críticas de nuestro poeta. Pero si hemos presentado este poema como introducción a un estudio sobre la crítica de arte de Baudelaire, es porque en estas estrofas se hallan contenidas la manera y la concepción originales con que Baudelairee abordará la obra de los pintores y que será erigida en método y sistema en la reseña sobre la exposición de 1855, Y porque la composición de este poema corresponde bien,en efecto, da la aseveración ya citada de Baudelaire : "la mejor reseña de un cuadro podría ser un soneto o una elegía".

Veremos pues como a lo largo de toda su obra Baudelaire propone una nueva concepción de la crítica de arte que, yendo contra la crítica clásica y académica, apegada al análisis frío y laborioso de los detalles de un cuadro, está basada al contrario en la impresión subjetiva y sintética suscitada por la composición del artista, en las resonancias póéticas que despierta en el alma del espectador no el detalle, sino el conjunto plástico, el halo dramático - poético que circunda al cuadro, su atmósfera especial, la composición total, en fin, que en el caso del buen cuadro se impone a la sensibilidad del espectador con fuerza ineluctable, de modo que la buena pintura debe gustar incluso cuando el que la considera está bastante alejado como para no poder distinguir, no solamente los detalles, sino, lo que es más, ni siquiera el tema de la composi- 
ción. Así en un cuadro de Delacroix parece como si una atmósfera mágica avanzara hacia el espectador y lo envolviera. Estas convicciones, y la concepción bastante nítida del cuadro que se desarrolla como una "melodía", son puntos capitales en los que Baudelaire se apoyará para esbozar a lo largo de su obra crítica una especie de Gestalt, Teoría de la pintura, punto importantísimo éste que reservamos para tratarlo luego con mayor detenimiento.

Será pues en la perspectiva de estas ideas claves, dentro de estos nuevos criterios que basan en la impresión subjetiva, en la vivencia directa, la consideración de la obra pictórica, como tendremos que seguir a Baudelaire en sus andanzas de crítico por museos y exposiciones. Pero esto nos impone una doble tarea, pues Baudelaire lejos de limitarse a la simple reseña crítica, seca Y técnica, de los grandes pintores del siglo XIX, halla asidero en las obras que critica, describe o comenta, o simplemente evoca, para exponer una vasta concepción estética (en el caso de Baudelaire no podemos hablar en absoluto de "un sistema" de estética : nuestro poeta fué antisistemático por excelencia), concepción en la que no falta nada, a no ser justamente -hace el caso repetirlo, y con insistencia, la pretensión meticulosa del sistema-: ni una teoría del color, ni un conjunto orgánico de ideas sobre el arte en general, ni una teoría particular sobre la naturaleza y el ideal, sobre lalunción del Zartista, ni un ccapítulo consagrado a la esencia de la comicidad. i Fa lotalidad de esta concepción está subordinada a una afirmación de creencia sin límites, a un verdadero acto de fe en.la omnipotencia y en el valor irreeemplazable de la imaginación, la que sobre todo trae consigo este trastornamiento total de los criterios sobre los cuales podrá basarse un crítico para juuzgar el arte: el juicio técnico y frío cederá entonces el paso al análisis apasionado, que será las más de las veces, una descripción temperamental y lírica que recrea, reforma y hace revivir el cuadro, poéticamente. El reconocimiento de la imaginación como principal valor de la creación artística, hará pues que la crítica se concentre principalmente en el valor dramático, humano y poético del cuadro; pero no por eso Baudelaire hará caso omiso de las exigencias técnicas. La gran imaginación demanda como complemento una gran pureza de ejecución, un buen dibujo, una armonía impecable dé colores. El gran pintor, por más poeta que sea, deberá ante todo saber pintar : pero saber pintar es justamente para Baudelaire no extraviarse en los mosaicos de detalles relamidos y 
técnicamente impecables, los cuales no llegan nunca a constituir un buen cuadro, porque les falta lo principal : a saber, la imaginación y la ingenuidad que dan a la obra de arte su unidad. Esto sentado, Delacroix será para Baudelaire el ideal perfecto del pintor : Delacroix, que unía a una imaginación desbordante una preocupación minuciosa por los instrumentos y la ejecución.

A partir de estas premisas se explicará la vehemencia con que Baudelaire insiste sobre el misterio, lo maravilloso, el ideal, el dra$\mathrm{ma}$, elementos que, al igual que en su poesía, están presentes en toda su obra crítica como un aura y una atmósfera que colora con una luz especial todos sus estudios. Esta obra crítica es vasta y compleja : abarca ella sola 20 años de estudio y de meditación. Como es evidente que en el caso de Baudelaire el crítico procede del poeta, nosotros trataremos de abordarla aquí separando su contenido en dos órdenes de problemas : las cuestiones preliminares que tratan sobre el arte en general, la esencia y la definición de lo bello, la concepción general de las bellas artes, etc., es decir, toda la categoría de cuestiones que a falta de un término más adecuado, podríamos llamar la "Estética" de Baudelaire, para pasar solamente luego a un análisis de la metodología crítica y de sus aplicaciones particulares a la obra de diferentes pintores.

La obra entera de Baudelaire está marcada por la obsesión permanente, por la búsqueda terca y agónica de la belleza, y es esta inquietud incesante, al mismo tiempo inconsciente y racional, sabia y a la vez ingénua, la que funde en suprema, unidad poética su obra en verso y su obra en prosa, de crítico literario y artístico. Hay pues en la obra de Baudelaire una voluntad infatigable, siempre renaciente, de interpretación estética del mundo. Pero la Estética que el poeta propone, vale decir, el modelo de belleza que persigue, rompe contínuamente con los cónones de la Estética, es decir, del sistema de la ciencia analítica de lo bello, (como toda ciencia clara, coherente, fría y ponderada) para desbordar en los dominios de la metafísica, de la magia y de la angustia dramática de la existencia. "La crítica - dice Baudelaire- colinda a cada instante con la metafísica". El poeta se siente así impulsado a buscar la esencia y la expresión de lo bello, en las formas y los aspectos más dramáticos y dolorosos de la vida del hombre. Lo bello será fundamentalmente drama: es decir, acción contrariada y difícil, tormento, en pleno camino de la aspiración hacia el ideal. Es innecesario hacer recalcar aquí cuán profundamente poética 
es esta concepción. "Lo bello —dice Baudelaire- es siempre extraño". Y el poeta expone en algunas líneas de extraordinario poder de sugerencia, un original conjunto de ideas sobre lo bello que pone en evidencia la fuerte ascendencia romántica de Baudelaire : lo bello consiste esencialmente en una serie de factores que podríamos llamar "dramáticos" y que excluyen todo ensayo de definición de la belleza por cualidades meramente plásticas. El método de definición es caracterizado por una enumeración (es éste el mismo método seguido por Baudelaire en sus estudios críticos sobre la pintura, que reposan en general en una enumeración de las impresiones producidas por la tonalidad general del cuadro sobre una sensibilidad poética) de los caracteres que determinan la belleza: "He encontrado la definición de lo Bello, de mi Bello. Es algo ardiente y triste, algo un poco vago, que deja margen a la conjetura". Para concretizar su pensamiento, Baudelaire pasa en seguida a aplicar sus "ideas" a un "objeto sensible" : el objeto "más interesante en la sociedad : una cabeza de mujer". Si es seductora y bella, hará sonar al mismo tiempo con la voluptuosidad y la tristeza (pero de manera confusa); "comporta una idea de melancolía, de lasitud, y hasta de saciedad - o bien una idea contraria, es decir un ardor, un deseo de vivir, asociados a una amargura que refluye, cual si viniera de la privación o de la desesperación" "También el misterio y la añoranza son caracteres de lo bello": Ina cabeza de hombre contendrá también "algo ardiente'y trister mente reprimidas - la idea de un poder rugiente y sin empleo algunas veces también, y es, - precisa Baudelaire- uno de los más interesantes caracteres de la belleza, el misterio : finalmente - acaba diciendo el poeta- "para tener el valor de confesar hasta qué punto me siento moderno en estética, la desdicha". Baudelaire concluye su definición de lo Bello, diciendo que, si bien la Alegría puede acompañar a la belleza, es, sin embargo, uno de sus adornos más vulgares. Y agrega: "No llego a concebir un tipo de belleza en el que no haya Desdicha".

Nos encontramos pues frente a un ideal de belleza que se define sobre todo por cualidades extra-visuales y extra-sensibles; 0 mejor dicho, en la cual las cualidades sensibles constituyen simplemente un punto de apoyo a partir del cual el hombre podrá intuir, detrás o más allá de la superficie densa del color y el modelado, el dominio de la espiritualidad, el drama incesante, el espíri- 
tu en busca de absoluto. Esta definición espiritual de lo bello, aplicada como ejemplo por Baudelaire a un objeto sensible natural : una cabeza humana, nos permite pasar sin transición al dominio del arte, pues ilustra y apoya a la vez la aseveración del crítico, quien, haciendo un estudio sobre el arte de Delacroix, afirma que la más notable de las cualidades de este pintor, y la que hace de él el verdadero pintor del siglo XIX es "la melancolía singular y obstinada que se exhala de todas sus obras". Esta afirmación, que condensa cabalmente lo esencial de las ideas estéticas de Baudelaire, debe ser puesta en relación con la simpatía profunda, visible a través de toda su obra, que manifiesta por el romanticismo: "La expresión más reciente, más moderna de la belleza". Así Delacroix, pintor romántico, realizará en la plástica el ideal estético de Baudelaire. El arte de Delacroix en efecto, esa pintura apasionada, atormentada, violenta, suscita en el poeta un entusiasmo sin límites, y es probable incluso que haya influído en cierto modo en algunas de sus concepciones estéticas. Sea como fuere, Baudelaire, al juzgar a Delacroix se contempla en su obra como en un espejo, y a trayés de los cuadros de las épocas sucesivas del pintor, encuentra confirmadas, condensadas en el color prodigioso de esta pintura, sus ideas supernaturales de una belleza dramática y marcada con el sello de la espiritualidad. Así, en juicios sucesivos, Baudelaire, en sus reseñas críticas de Delacroix, va afirmando su concepción particular de lo bello, que consiste en la más o menos feliz disposicióni de vỏlúmenes, lde formas, de detalles del color o de la línea, sino en la fuerza dramática y poética ingerente al espíritu. Por eso el poeta insiste tanto en las cualidades extra-sensibles del gran pintor francés: "La pintura de Delacroix -por ejemplo- revela el supernaturalismo". "El dibujo de Delacroix es movimiento"; "Delacroix es poeta, es literario". Nadie como Delacroix, después de Shakespeare puede fundir así en misteriosa unidad el drama y el ensueño. La pintura de Delacroix es melodía y armonía; Delacroix proyecta a la distancia de manera mágica su pensamiento; Delacroix traduce lo invisible, lo impalpable, el sueño, los nervios, el alma; su pintura es poética, dramática; Delacroix posee un arte mágico que le ha permitido traducir las palabras en imágenes plásticas", etc. En una palabra, la pintura de Delacroix aparece a nuestro autor como una fusión de carácter superior, en la que convergen magia, poesía y drama. Será útil confrontar a este respecto las ideas de Baudelaire sobre 
el retrato: también el retrato es una biografía dramatizada, un drama natural inherente a todo hombre : ahí radica su belleza, y la cualidad fundamental del retratista habrá de consistir, por consiguiente, en saber traducir en la tela, la fuerza y la pasión de este drama interior. Pues la pasión es también parte integrante de lo Bello, y "el elemento particular de cada belleza viene de las pasiones".

Dadas estas premisas, y siendo la belleza en general, función de la espiritualidad, toda obra de arte digna de tal nombre vendrá a colocarse forzosamente bajo el signo de la idealidad. En efecto, el artista al crear no puede crear sino ideal. Pero el ideal -dice Baudelaire- no es esa cosa vaga, ese sueño aburrido e impalpable que nada en el cielo raso de las academias; un ideal es el individuo reformado por el individuo, reconstruído y devuelto por el pincel $\circ$ el cincel a la fulgurante verdad de su armonía nativa". El ideal estará entonces en cada individualidad concreta, será la posibilidad de actualización de la totalidad, de la esencia de un individuo: y ahí se sitúa precisamente la magia del arte: el arte traduce concretamente en color, en línea o en volumen el ideal que en cada individuo tiende a su realización. El artista se sitúa entonces en la línea que delimita los dominios de la naturaleza y el espíritu para realizar la síntesis original de su obra. La pintura, según Baudelaire, es justamente la síntesis entre la naturaleza y el espíritu, concepción esta donde es imposible no distinguir la sorprendente analogíáconl fa teoría de Hegel, Sëgún la cual la pintura es el único arte que puede expresar en el exterior la plena interioridad, es decir, el arte en el cual se logra el equilibrio ideal y ponderado entre la interioridad del espíritu humano y la lisa exterioridad de las cosas. Esto ilustra, dicho sea de paso, la indiferencia con que Baundelaire habla de la escultura (todo un capítulo del . salón de 1846 es consolado a explicar al lector "por qué la escultura es aburrida") : mientras que la pintura es "un arte de razonamiento profundo" para gozar, del cual se necesita 'una iniciación particular", la escultura es un arte de primitivos, un arte que no ha llegado a desligarse de la naturaleza, e incluso, salida ya de la época salvaje, en su "más espléndido desarrollo" la escultura sigue siendo un arte complementario: "brutal y positiva como la naturaleza", es al mismo tiempo como ella "vaga e inasible". Es pues la pintura - "arte romántico" según Hegel - la que habrá de realizar la verdadera síntesis entre el espíritu huma- 
no y el mundo exterior al espíritu. Pero para realizar esta síntesis es necesaria una facultad especial : la imaginación, "reina de las facultades". Si la imaginación falta, todo falta; si la imaginación existe, el resto cuenta poco, y las demás facultades se subordinarán a la imaginación que, dominadora, absoluta, crea y ordena, gobierna y dispone, interpreta e idealiza. La primera cualidad, pues, de un pintor, de un artista en general será de ser imaginativo. La naturaleza, en efecto, es un diccionario. Baudelaire citó a menudo esta frase de Delacroix y el primer cuarteto del soneto "Correspondencias" en "Las Flores del Mal" ofrece, como se sabe una estupenda ampliación poética de esta idea:

La nature est un temple où de vivants piliers

Laisent parfois sortir de confusses paroles;

L'homme y passe ã travers des forêts de symbôles

Qui l'observent avec des regards familiers.

Baudelaire nos introduce asi en un universo que es por esencia simbólico y significativo, pero solamente a condición de ser comprendido por el espíritu humano, que otorga a cada cosa su valor, a cada ser su jerarquía particular. Es a través de la imaginación como se realizará este proceso de interpretación simbólica. "Todo el universo visible - afirma Baudelaire - no es sino un almacén de imágenes ýtecsímbolos, alos cuáles la imagina-

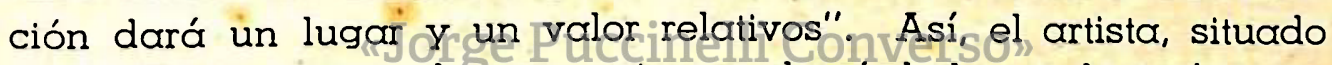
en el límite mismo de este universo de símbolos y de imágenes, deberá entregarse, asistido por la imaginación, a un trabajo incesante de interpretación y de recreación imaginativa de los seres y de las cosas naturales. El resultado de este proceso será justamente la obra de arte que reflejará, que contendrá, como una verdadera creación espiritual, el contenido del espíritu mismo del artista, envuelto en la atmósfera densa y transparente a la vez de la cualidad sensible: una cualidad sensible enteramenie penetrada y hecha transparente por el espíritu. La síntesis entre la naturaleza y el hombre estará así lograda, y lo estará gracias a la facultad misteriosa de la imaginación.

Se trata pues aquí de una imaginación realmente creadora que, permitiendo a través de un hacimiento confuso de signos $y$ de imágenes, dar la existencia a un universo nuevo y lleno de sentido, afrece al hombre, en la breve síntesis de la mirada y el acto 
que es una obra de arte, el testimonio más cabal de su dignidad. En cuanto al otro artista, el que llamándose a sí mismo realista, trata simplemente de imitar a la naturaleza, el artista del detalle meticuloso, de cuya obra todo sueño, todo misterio y todo sentido de lo "supernatural" están ausentes, Baudelaire se limita a acordarle un soberano desdén. Este hombre pintará al universo sin el hombre, un universo, por consiguiente, que no merece en absoluto ser pintado. El artista imaginativo, al contrario, dice: "Yo quiero iluminar las cosas con $\mathrm{mi}$ espíritu y proyectar su reflejo sobre los otros espíritus". Solamente en este caso el arte será una aventura a la medida del hombre y de su sed de absoluto.

Baudelaire nos introduce así en una Estética profundamente penetrada de espiritualidad, en la cual el artista ocupa el lugar de un sacerdote del misterio. De ella deriva toda una concepción y un método de la composición de la obra de arte. Pintando la naturaleza, el pintor pinta su estado de ánimo. El punto de partida será una idea generadora y central, suscitada por la inteligencia intima del tema. En torno a este núcleo se irán disponiendo todos los demás elementos de la composición, que se subordinarán dócilmente a la rigurosa unidad jerárquica de la idea central : "Todo, - dice Baudelaire - habrá de servir a iluminar la idea generadora". "Como un sueño está colocado en una atmósfera que le es propiapasí una concepción hecha composición, deberá moverse en un medio coloreado que le sea particular". Baudelaire investiga puesoragénesisindel lcuadróaspartir de la concepción -original en cada creación singular- y que es producto puro y simple de la imaginación. El cuadro es así "creado por un sueño" y tiene que permanecer fiel a este sueño. Sobre esta base, el poeta nos describe un proceso de composición de la obra de arte, en la cual ésta se va transformando poco a poco, mediante "creaciones" sucesivas, por la adición de "capas" que se agregan, una tras otra, a la idea primitiva. En síntesis, la obra de arte "es producida - concluye Baudelaire- como un mundo". Un cuadro es en realidad "una serie de cuadros superpuestos".

Nos hemos referido a la Gestalt-Teoría, hablando de las concepciones de Baudelaire sobre la pintura. Deberemos explicarnos sobre la introducción de este término tomado de la psicología moderna, aplicado por nosotros a las ideas estéticas de Baudelaire. Sabemos que la Psicología de la Forma se basa en la consideración de estructuras que son algo diferente y algo más que la 
simple suma de sus partes, y en las cuales los detalles que conforman un todo, no tienen valor sino por la unidad estructural y orgánica que les es anterior. La analogía entre las ideas estéticas del autor de "Les Fleurs du Mal" y esta concepción psicológica es sorprendente. Como Ehrenfels, en sus estudios de pionero sobre la Psicología, y a partir de él define, el proceso de composición pictórica. La melodía "es la unidad en el color o el color general" y su tendencia característica es la conclusión. La melodía tiende a la conclusión, debe ser concluída, "es un conjunto donde todos los efectos concurren a un efecto general". Y así la buena manera de saber si un cuadro es melodioso (es decir, si es positivamente una estructura) "es mirarlo de bastante lejos como para no comprender ni el tema ni las líneas". Si es melodioso -agrega Baudelaire - tiene ya un sentido y ha tomado ya su sitio en el repertorio de los recuerdos". Dentro de esta perspectiva, el arte será para nuestro poeta una "abstracción", y "un sacrificio del detalle al conjunto". Es pues una verdadera concepción sintética y estructural del arte y de la realidad la que cierra, con sólido broche, la concepción estética de Baudelaire. Hay que señalar además que es en esta visión sintética del arte, donde se realiza para Baudelaire la reconciliación entre la naturaleza (es decir la materia) y el artista (es decir el espíritu). Como el cuadro del gran artista no ofrece sino estructuras coloreadas donde el detalle y la línea se desvanecen subordinados a loedeacentral que ordena el conjunto, así la naturaleza no ofrece sino masas de colores, volúmenes, harmonías de conjuntos, grandes síntesis, en suma, a partir de las cuales el análisis racional y técnico no llega a separar sino a posteriori el color de la línea. La síntesis, la estructura total, son pues lo prístino y lo original, y esto explica que el buen pintor, cuyo método es propiamente el método de la naturaleza, (recordemos aquí la expresión : "un cuadro es creado como un mundo"), produce una síntesis total en que la línea es inseparable del color, porque "al colorear, dibuja". El verdadero gran dibujanite será el colorista que, de un solo pincelazo magistral, presenta, fundidos en una unidad que no se puede descomponer, el color y la línea; el colorista, pues, que trabaja como la naturaleza misma, parte de una intuición global, cuyo resultado será traducido por su obra en una unidad plástica que.se impondrá con el carácter de lo bello previamente a todo conato de análisis : la diversidad multiforme de la naturaleza será devuelta así, en la melodía mis- 
teriosa de un cuadro, a su unidad primera. El artista que utiliza el método contrario, en cambio, (Baudelaire designa expresamente a Ingres), partirá de un análisis a priori y tratará de lograr una síntesis artificial, trazando primero líneas de pureza impecable, y adaptando los colores en un segundo tiempo a las superficies delimitadas por esas líneas. En este caso las líneas carecerán de movimiento, y los colores carecerán de vida. El arte supone, como la realidad, en su base misma, un sentido primigenio de la estructura, una síntesis original, que dominan tanto en la naturaleza como en el espíritu.

Es basándonos en esta concepción profunda de la síntesis en el arte y en la vida, como podremos seguir ahora, para terminar, las líneas generales del método crítico de Baudelaire. Al proceso - al método sintético de creación de la realidad y del arte deberá corresponder un criferio estético que permita juzgar la obra de creación. Aunque Baudelaire se negó siempre de manera pertinaz a encerrarse, en su labor de crítico, en los límites estrechos de un criterio cualquiera, fabricado de antemano, resulta evidente que este criterio existe, y está presente en toda su obra de crítico, y es para el sentimiento: el medio de comprensión sintético por excelencia. "Es solamente por el sentimiento como debéis comprender el arte", afirma categóricamente Baudelaire. En efecto, desde su primerajieseña crítica sobre el salón de 1845, el poeta se deja guiar por la impresión subjetiva para juzgar del valor de los cuadros"presentados.ll"Desde un Comienzo, dice la Dra. Lucie Horner en su estudio sobre "Baudelaire, crítico de Delacroix", es claro que el juicio estético de Baudelaire no es obstaculizado por principios de ninguna escuela, sino que se despliega, por el contrario, independientemente de todo criterio tradicional". Baudelaire basará pues la crítica en la impresión subjetiva, en la mayor o menor intensidad de las evocaciones poéticas que suscitan en él los cuadros de los pintores que comenta, lo que le permitirá dejar de lado la descripción técnica de la obra con su secuela inevitable de vocablos especializados, para consagrarse a un análisis libre, las más de las veces de carácter poético, interrumpido a menudo por digresiones sobre problemas de estética general, de filosofía - de moral. . El poeta confronta así su ideal estético, con el ideal realizado por el cuadro que se halla ante él, y de esta fusión brota el juicio, en general corto, somero, conciso y que se apoya ante todo en la impresión subjetiva, a la que sirve de horizonte el edi- 
ficio completo de las ideas estéticas y filosóficas del crítico. Aunque presente ya en sus primeras obras, este método de crítica por la impresión subjetiva no fué expuesto y racionalmente defendido por Baudelaire, sino en la reseña crítica sobre la Exposición Universal de 1855, cuyo primer capítulo se llama justamente "Método de Crítica". Baudelaire comienza por contraponer el sistema a la espontaneidad natural de la vida y del espíritu. Vale la pena citar el texto completo: "He tratado más de una vez, como todos mis amigos, de encerrarme en un sistema, para predicar desde ahí a mi antojo. Pero un sistema es siempre una especie de condenación que nos impulsa a una abjuración perpétua: siempre hay que inventar otro, y esta fatiga es un cruel castigo. Y siempre mi sistema era bello, vasto, espacioso, cómodo, limpio y liso, sobre todo; por lo menos a mí me parecía tal. Y siempre un producto espontáneo, inesperado, de la vitalidad universal, venía a dar un desmentido a mi ciencia infantil y envejecida, hija deplorable de la utopía. Por más que moviera o extendiera al criterio, éste estaba siempre atrasado por relación al hombre universal, y corría sin cesar tras la belleza multiforme y versicolora que se mueve en las espirales infinitas de la vida. Condenado sin cesar a la humillación de una nueva conversión, tomé entonces una gran decisión. Para escapar al horror de estas apostasías filosóficas, me he resignado orgullosamente a la modestia: me he contentado con sentir; he vuelto a buscar un asilo en la impecable ingenuidad". Obvio es decir que, partiendo de semejante declaración de principios, el método de Baudelaire evitará, como la misma peste, todo academismo y toda insistencia sobre el detalle técnico : la erudición pareciéndole ser en muchos casos "pueril y poco demostrativa por naturaleza", Baudelaire crítico preferirá hablar "en nombre del sentimiento, de la moral y del placer".

Así se expresa textualmente el poeta. En realidad, al aplicar en toda circunstancia el método crítico de la impresión subjetiva, Baudelaire exige que el buen cuadro llene ciertas condiciones en concordancia con su aguda sensibilidad poética. El juicio será favorable o desfavorable según que el cuadro realice $\circ$ no esas condiciones. La primera de ellas es naturalmente la imaginación, a la que ya nos hemos referido. "La imaginación es la reina de la verdad y se aparenta positivamente con lo infinito". Y el buen pintor, para Baudelaire, es un pintor de lo infinito. Juzgando a Ingres, nuestro crítico afirma que la impresión que se desprende 
de sus cuadros es "negativa": "le falta la imaginación". Es útil hacer recalcar, sin embargo, que aunque el juicio que merecía Ingres a Baudelaire era más bien desfavorable, el poeta se expresa siempre sobre él en los términos del mayor respeto: Baudelaire reconoce en Ingres la maravillosa calidad de su dibujo impecable, y comprende su ideal obstinado de una belleza pura e inmóvil. Esto demuestra como el crítico de la "impresión subjetiva" sabía ser objetivo frente a los grandes talentos. Solamente, el ideal pictórico de Ingres se encontraba en el polo opuesto del de Baudelai-

Es Delacroix, por el contrario, quien, como ya hemos dicho, realiza plenamente este ideal : Delacroix, el pintor de la imaginación. Veamos algunas muestras concretas de juicios de Baudelaire sobre Delacroix, en las cuales aparece, en toda su luz característica, la manera especial de la crítica de Baudelaire, que consiste en aislar la impresión general producida por el espíritu íntimo del cuadro, mediante una enumeración de cualidades a menudo extra visuales :

LA MAGDALENA EN EL DESIERTO : "Es una cabeza de mujer echada hacia atrás, en un cuadro muy estrecho. A la derecha, en lo alto, un fragmento de cielo, o de roca algo azul; -los ojos de la Magdalena están cerrados, la cabeza es muelle y lánguida, los cabellos están esparcidos. Näadie, a menos de verla, puede imaginarse lo que el artista ha puesto de poesía íntima, misteriosa y romántica, en cesta simplèlcabèzá.nverso"

Ultimas palabras de MARCO AURELIO : "Marco Aurelio lega a su hijo a los estoicos. Está semi desnudo, agonizante, y presenta al joven Cómodo, joven, rosado, blando y voluptuoso, y que tiene cara de aburrirse, a sus severos amigos agrupados en torno de él en actitudes desoladas. Cuadro espléndido, magnífico, sublime, incomprendido".

SAN SEBASTIAN : "Es una maravilla, no solamente como pintura, es también una delicia de tristeza".

Hemos entresacado estos tres ejemplos de juicios cortos para mostrar como Baudelaire sintetiza el espíritu general de un cuadro, en una enumeración que es al mismo tiempo una descripción objetiva y una interpretación subjetiva. Estos dos factores resu- 
men perfectamente, a nuestro juicio, lo principal de la técnica crítica de Baudelaire.

Por último, la segunda condición que debe llenar un buen cuadro consiste en la ingenuidad, por la cual Baudelaire está obsedido desde sus primeros ensayos críticos del salón de 1895. Esta "impecable ingenuidad" es la calidad del pintor que ha sabido desprenderse de las preocupaciones pedantes de escuela y de taller. Por eso el espíritu del gran artista se aproxima al espíritu de la infancia: el genio "no es sino la infancia reencontrada a voluntad". Para el niño todo es novedad; para el artista también; el niño está siempre ebrio: el artista también. Será pues esta capacidad, que el artista comparte con el niño y que el crítico comparte con el artista, de zambullir en la impresión fresca y pura, de mirar a los seres y las cosas con mirada siempre nueva, no deformada por cánones ni reglas de ninguna escuela, de ninguna secta, la que servirá como último criterio y como piedra de toque para el juicio estético. Y Baudelairé crítico reencuentra una vez más a Baudelaire poeta afirmando profundamente que "el juguete es la primera introducción a la Estética", y a través de las series de cuadros, ingénuos o tristes, - atormentados o claros, el poeta nos conduce por la mano hacia el paraíso de poesía olvidado en un rincón del cerebro de los hombres, a la región en que todo no es "sino orden y belleza, lujo calma y voluptuosidad".

Las concepciones estéticas de Baudelaire nos han conducido a su método críticó, qur su método crítico nos há SPlevado de nuevo a situarnos en la perspectiva de su universo poético. Es que en Baudelaire todo parte de la poesía y todo retorna a la poesía como a su lugar natural. No creemos pues pecar por exagerados si decimos que la obra crítica de Baudelaire es uno de los más hermosos poemas de la literatura universal. Y en primer lugar, debemos ponernos de acuerdo sobre los términos. La gran conclusión que se puede sacar de los escritos críticos del poeta es, ante todo, que la crítica no sirve para nada. Queremos decir, la crítica en sí, aquella que hace profesión de ser crítica y solamente crítica, es decir que se pretende imparcial y fría, serena, desligada de la pasión y de la simpatía. Análisis que, no satisfaciendo al sentimiento, no satisface nada en absoluto. Intuitivo como pocos lo han sido, para Baudelaire el arte fué cuestión de vida o muerte, pasión quemante que le retorcía los nervios, y así su actitud ante la pintura no fué nunca la del ponderado abstractor de quinta 
esencia, sino la del admirador deslumbrado, o la del hombre lleno de cólera o de desdén. Frente a un pintor, Baudelaire ve en él a un amigo o a un enemigo, o a ninguno de los dos, es decir a un imbécil. La crítica con todo su fárrago de tecnicismos es dejada de lado como un pasatiempo de pedantes, y Baudelaire se limila a sentir, perfectamente circundado de soledad. Por eso todo su esfuerzo de comprensión, loda su simpatía y su sensibilidad, se concentran alrededor de esa aura de drama, de ese misterio doloroso e ingenuo que circunda como un ambiente vagamente luminoso la obra de todo gran artista. Sentirlo y trasponerlo en un lenguaje mágico, todo traspasado de simpatía y de pasión, he ahí el secreto de la crítica de Baudelaire, Arte: poesía... : misterio. La otra crítica, la periodística, la prosaica, es relegada desdeñosamente a su vago dominio, entre la superficialidad de la curiosidad del "amateur" y la vanidad burguesa de las notas sociales, y sus juicios, juicios para el uso de una sociedad de comerciantes con veleidades de ilustración, no tienen nada que hacer, ningún papel que desempentar, cucindo el poeta, señero frente a una creación señera, devuelye la obra de arte a su tierra de origen : la poesía, e inicia, fuera de toda circunstancia temporal, el diálogo secreto de dos subjetividades, en que el alma se pone a hablar a solas con el alma, su lenguaje de símbolos, "de silencio y de noche.

La obra, pues, que comentamos, es una lección : una lección de espiritualidad dada a una épolca ya dominada por la fotografía $y$ el periodiśmog y Pel creálismo servileded progresismo, por un pensador que se estremecía al constatar - hace cien años- que "el progreso es la dominación progresiva de la materia".

Partiendo de la constatación casi experimental de que la pintura es una interpretación simbólica de la realidad, lograda en un proceso en que el espíritu, intuyéndose a sí mismo, inunda la materia de su propia luz, Baudelaire restablece la jerarquía natural de los seres y las cosas, la jerarquía también de los valores del espíritu, en un mundo cada vez más alejado de la verdadera realidad, por la ausencia creciente de imaginación. "En este culto abobado de la naturaleza, no depurada, no explicada por la imaginación, veo un signo evidente de rebajamiento general", decía el poeta en un estudio sobre el paisaje.

Con el amor de la pintura en los nervios, según su propia expresión, Baudelaire realiza un esfuerzo agónico para devolver a la pintura su lugar privilegiado de portavoz de la imaginación, de 
conciliariora, de acto sintético entre el hombre y la naturaleza, y, al hac€rlo, reinstala al espíritu en su dignidad primera de creador y dispensador de belleza.

Baiıdelaire intuye así el arte como un proceso eterno en que el artista recrea el universo en su obra, la cual es recreada a su vez por i:ada subjetividad particular que, frente al misterio insondable de 'a creación artística, recomienza siempre en la soledad perfecta, en la confrontación desnuda del espíritu con el espíritu, el diálogo silencioso de la belleza cuyos ecos se retransmiten de generación en generación y no podrá tener fin sino con la extinción del hombre y de la sed de infinito que lo mueve :

Car c'est vraiment, Seigneur, le meilleur témoignage

Que nous puissions donner de notre dignité

Que cet ardent sanglot qui roule d'âge en âge

Et va mourir au bord de votre éternité!

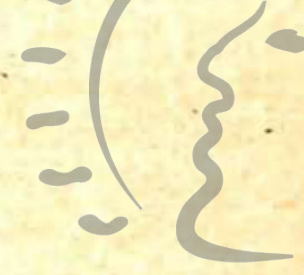

Biblioteca de Letras

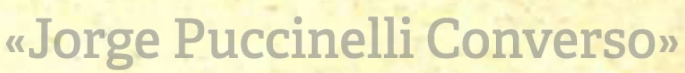

